\section{Erratum}

https://doi.org/10.11646/zootaxa.5100.4.9

http://zoobank.org/urn:lsid:zoobank.org:pub:06BD5933-2F04-4F69-A55F-149694B7F03B

\title{
MING KAI TAN, RAZY JAPIR, ARTHUR Y. C. CHUNG \& RODZAY BIN HAJI ABDUL WAHAB (2021) New species and taxonomic notes of scaly crickets (Orthoptera: Mogoplistidae: Mogoplistinae) from Borneo. Zootaxa, 5048: 407-421.
}

On page 410:

The measurements of Cycloptiloides bimaculata Tan, Japir \& Chung, sp. nov. are incorrect and should be replaced with: "Measurements (in mm). Holotype $\mathrm{BL}=6.2 ; \mathrm{FRW}=0.4 ; \mathrm{SW}=0.2 ; \mathrm{EW}=0.2 ; \mathrm{PL}=3.0 ; \mathrm{PW}=2.1 ; \mathrm{HFL}=$ 4.0; $\mathrm{HFW}=1.4 ; \mathrm{HTL}=2.9 ; \mathrm{HML}=1.3 . "$

On page 414:

The description of Ectatoderus nigrofasciatus Tan \& Wahab, sp. nov. is incorrect: "Medial valve elongated, not curved to a spiral, sinuous both dorso-ventrally and laterally." It should be replaced with "Medial valve elongated, curved to a spiral, apical part sinuous both dorso-ventrally and laterally."

On page 416:

The measurements of Ectatoderus nigrofasciatus Tan \& Wahab, sp. nov. are incorrect and should be replaced with: "Measurements (in mm). Holotype $\mathrm{BL}=12.2 ; \mathrm{FRW}=0.4 ; \mathrm{SW}=0.4 ; \mathrm{EW}=0.4 ; \mathrm{PL}=6.2 ; \mathrm{PW}=3.5 ; \mathrm{TL}=$ $3.7 ; \mathrm{HFL}=6.9 ; \mathrm{HFW}=2.1 ; \mathrm{HTL}=6.4 ; \mathrm{HML}=1.4 . "$

The scale bars in the figure captions are incorrect and should be replaced accordingly as shown below:

On page 409:

FIGURE 1. Scale bars: $1.6 \mathrm{~mm}$

On page 412:

FIGURE 3. Scale bar: $1.6 \mathrm{~mm}$

On page 413:

FIGURE 4. Scale bars: $1.6 \mathrm{~mm}$ (all except B), $0.8 \mathrm{~mm}$ (B)

On page 415:

FIGURE 6. Scale bars: $1.6 \mathrm{~mm}$

On page 417:

FIGURE 7. Ectatoderus nigrofasciatus Tan \& Wahab, sp. nov. apical half of the male phallic complex in dorsal (A), ventral (B), lateral (C) and latero-ventral (D) views; and apex of medial valve in ventral view (E). Scale bars: $1.6 \mathrm{~mm}(\mathrm{~A}-\mathrm{D}), 0.8 \mathrm{~mm}(\mathrm{E})$

On page 419:

FIGURE 9. Scale bar: $1.6 \mathrm{~mm}$

On page 420:

FIGURE 10. Scale bar: $1.6 \mathrm{~mm}$ 